\title{
Uterine Tumors and PET-CT
}

\author{
Prof. Dr. Raihan Hussain, MBBS, DNM, MACR, FANMB, Ph D. \\ National Institute of Nuclear Medicine and Allied Sciences, BAEC \\ Bangabandhu Sheikh Mujib Medical University Campus, Dhaka.
}

At the first instance the title may be a bit surprising as uterus is not a frequently visited domain in Nuclear Medicine. Ultrasonogram has taken over all sort of imaging modalities as it is simple, inexpensive technique. But along with other anatomical imaging procedures like CT or MRI, it cannot provide the functional and metabolic information. Here Positron emission tomography Computed Tomography (PET-CT) can play useful roles.

The most common uterine tumors include leiomyoma (benign) and endometrial carcinoma (malignant). There are times when preoperative differentiation is needed. FNAC is not an easy option for uterine tumors. PET-CT with metabolic and receptor tracers can help us in this regard.

PET-CTwith fluorine 18 (18F) fluorodeoxyglucose(FDG) has been used for diagnosis of gynecologic malignant tumors and is considered to be superior to conventional imaging methods in diagnostic accuracy for detection of metastatic lesions and local recurrence (1-5). The size of the tumorand inflammatory changes of the lesion may affect PET imaging and FDG accumulation. FDG uptake is also affected by the menstrual cycle as well $(6,7)$. Additional physiologic information other than glucose metabolism may improve the diagnostic accuracy of PET.

Uterine leiomyomas usually show mild FDG uptake (8). Although the exact mechanism responsible for FDG uptake in leiomyomas is unclear, the phenomenon would be regulated by several factors including hormonal dependency, cellularity (the number of viable tumor cells), vascularity (microvessel density), tumor cell proliferation (the expression of growth factors such as basic fibroblast growth factor, transforming growth factor $\beta$, granulocytemacrophage colony-stimulating factor, and Ki-67 and their receptors), expression of glucose transporter 1 (GLUT-1) and hexokinase, the existence of endometrial tissue, and the presence of inflammatory cells $(9,10)$.

Receptor imaging is a new trend in Nuclear Medicine. There are two types of estrogen receptors in the body (Er $\alpha$ and ER $\beta)$. 16-[18F]fluoro-17-estradiol (FES)is an 18F-labeled compound of estradiol, the most bioactive type of estrogen, and is used for the detection of estrogen receptor (ER)-positive organs and diseases $(11,12)$. FES PET imaging is well established in patients with ERpositive breast cancer for diagnosis, staging, and post therapeutic follow-up (13-18). Investigators in previous studies (13-15) reported that FES accumulation was well associated with the concentration of ER in in vitro measurements, and it could therefore enable in vivo non-invasive measurement of ER density. In benign lesions the receptor are intact but in malignant tissues due to its anaplasia the receptors are lost, hence the receptor tracers are poorly taken up.

Endometrial cancer generally shows intense FDG uptake. Kitajima et al. (19) reported that the mean SUV of endometrial cancer in 40 patients was $11.2 \pm 5.9$ (SD) (range: 2-25.6). PET-CT is a useful technique for assessing distant metastases throughout the whole body in a single examination in patients with advanced-stage disease. PET-CT can often detect normal-sized lymph node metastases from 5-9 mm, which conventional CT and MRI cannot diagnose.

ER expression and glucose metabolism of uterine tumors measured by using PET show opposite patterns between benign and malignant lesions. 18F-labeled FES is an analog of estradiol, and FES accumulation is well correlated with the concentration of ER in in vitro measurements (13-15). Because FES PET is used for the detection of ER expression in estrogen-related diseases such as breast cancer (13-18), it is possible to measure in vivo ER density noninvasively. On the other hand, FDG is a glucose analogue that reflects the activity of glucose transport proteins and the intracellular phosphorylation by hexokinase (20). PET studies with both FES and FDG can provide pathophysiologic information for the differential diagnosis of uterine endometrial neoplasias (endometrial carcinoma and hyperplasia) and myometrial tumors (sarcoma and leiomyoma). 
Tsujikawa et.al. (21) showed in a study, malignant endometrial tumors showed higher FDG and lower FES accumulation, a finding that was in contrast to that for benign lesions, which showed high FES and low FDG uptake. These results indicate the possibility of noninvasive differential diagnosis for endometrial lesions by using PET.

\section{REFERENCES}

1. Reinhardt MJ, Ehritt-Braun C, VogelgesangD, et al. Metastatic lymph nodes in patients with cervical cancer: detection with MR imaging and FDG PET. Radiology 2001;218: 776-782.

2. Yoshida Y,Kurokawa $\mathrm{T}$, Kawahara $\mathrm{K}$, et al. Incremental benefits of FDG positron emission tomography over CT alone for the preoper-ative staging of ovarian cancer. AJR Am J Roentgenol 2004;182:227-233.

3. Kurokawa T, Yoshida Y, Kawahara K, et al. Expression of GLUT-1 glucose transfer, cellular proliferation activity and grade of tumorcorrelate with [F-18]-fluorodeoxyglucose uptake by positron emission tomography in epithelial tumors of the ovary. Int J Cancer 2004;109:926-932.

4. Pandit-Taskar N. Oncologic imaging in gynecologic malignancies. J Nucl Med 2005;46:1842-1850.

5. Chao A, Chang TC, Ng KK, et al. 18F-FDG PET in the manage-ment of endometrial cancer. EurJ Nucl Med Mol Imaging 2006;33: 36-44.

6. Lerman H, Metser U, Grisaru D, et al. Normal and abnormal 18F-FDG endometrial and ovarian uptake in pre- and postmeno-pausal patients: assessment by PET/CT. J Nucl Med 2004;45:266-271.

7. Nishizawa S, Inubushi M, Okada H. Physiological 18F-FDG uptake in the ovaries and uterus of healthy female volunteers. EurJ Nucl Med Mol Imaging 2005;32:549-556.

8. Kitajima K, Murakami K, Kaji Y, Sugimura K. Spectrum of FDG PET/CT Findings of Uterine TumorsAJR Am J Roentgenol 2010; 195:737-743.

9. Nishizawa S, Inubushi $\mathrm{M}$, Kido $\mathrm{A}$, et al. Incidence and characteris-tics of uterine leiomyomas with FDG uptake. Ann Nucl Med 2008; 22:803-810.
10. Kitajima K, Murakami K, Yamasaki E, Kaji Y, Sugimura K. Standardized uptake values of uterine leiomyoma with 18F-FDG PET/CT: variation with age, size, degeneration, and contrast enhancement on MRI. Ann Nucl Med 2008; 22:505-512.

11. Kiesewetter DO, Kilbourn MR, LandvatterSW, Heiman DF, Katzenellenbogen JA, Welch MJ. Preparation of four fluorine18-labeled estrogens and their selective uptake in target tissue of immature rats. J Nucl Med 1984;25:1212-1221.

12. Mankoff DA, Tewson TJ, Eary JF. Analysis of blood clearance and labeled metabolites for the estrogen receptor tracer [F-18]-16 alpha-fluoroestradiol (FES). Nucl Med Biol 1997;24:341-348.

13. MintunMA, Welch MJ, Siegel BA, et al. Breast cancer: PET imaging of estrogen receptors. Radiology 1988;169:45-48.

14. McGuire AH,Dehdashti F, Siegel BA, et al. Positron tomographic assessment of 16 alpha-[18F] fluoro-17 beta-estradiol uptake inmetastatic breast carcinoma. J Nucl Med 1991;32:1526-1531.

15. Dehdashti F, Mortimer JE, Siegel BA, et al. Positron tomographic assessment of estrogen receptors in breast cancer: comparison with FDG-PET and in vitro receptor assays. J Nucl Med 1995;36:1766-1774.

16. Dehdashti F, Flanagan FL, Mortimer JE, Katzenellenbogen JA, Welch MJ, Siegel BA. Positron emission tomographic assessment of "metabolic flare" to predict response of metastatic breast cancer to antiestrogentherapy. Eur J Nucl Med 1999;26:51-56.

17. Mortimer JE, Dehdashti F, Siegel BA, Trinkaus K, Katzenellenbo-gen JA, Welch MJ. Metabolic flare: indicator of hormone respon-siveness in advanced breast cancer. J ClinOncol 2001;19:2797-2803.

18. Linden HM, Stekhova SA, Link JM, et al. Quantitative fluoroestradiol positron emission tomography imaging predicts response to endocrine treatment in breast cancer. J ClinOncol 2006;24:2793-2799.

19. Kitajima K, Murakami K, Yamasaki E, et al. Accuracy of FDG $\mathrm{PET} / \mathrm{CT}$ in detecting pelvic and paraortic lymph node metastasis in patients with endometrial cancer. AJR 2008; 190:1652-1658.

20. Chung JK, Lee YJ, Kim C, et al. Mechanisms related to [18F]fluo-rodeoxyglucose uptake ofhuman colon cancers transplanted in nudemice. J Nucl Med 1999;40:339-346.

21. Tsujikawa T, Yoshida Y,Mori T, et al. Uterine tumors: pathophysiologic imaging with $16 \alpha-[18 \mathrm{~F}]$ fluoro-17 $\beta$-estradiol and 18F-fluorodeoxyglucose PET—initial experience. Radiology 2008; 